\title{
The Effect of a Computer Simulation Activity versus a Hands-on Activity on Product Creativity in Technology Education
}

\author{
Kurt Y. Michael
}

Computer use in the classroom has become a popular method of instruction for many technology educators. This may be due to the fact that software programs have advanced beyond the early days of drill and practice instruction. With the introduction of the graphical user interface, increased processing speed, and affordability, computer use in education has finally come of age. Software designers are now able to design multidimensional educational programs that include high quality graphics, stereo sound, and real time interaction (Bilan, 1992). One area of noticeable improvement is computer simulations.

Computer simulations are software programs that either replicate or mimic real world phenomena. If implemented correctly, computer simulations can help students learn about technological events and processes that may otherwise be unattainable due to cost, feasibility, or safety. Studies have shown that computer simulators can:

1. Be equally as effective as real life, hands-on laboratory experiences in teaching students scientific concepts (Choi and Gennaro, 1987).

2. Enhance the learning achievement levels of students (Betz, 1996).

3. Enhance the problem solving skills of students (Gokhale, 1996).

4. Foster peer interaction ( Bilan, 1992).

The educational benefits of computer simulations for learning are promising. Some researchers even suspect that computer simulations may enhance creativity (e.g., Betz, 1996; Gokhale, 1996; Harkow, 1996), however, after an extensive review of literature, no empirical research has been found to support this claim. For this reason, the following study was conducted to compare the effect of a computer simulation activity versus a traditional handson activity on students' product creativity.

\section{Background}

\section{Product Creativity in Technology Education}

Historically, technology educators have chosen the creation of products or projects as a means to teach technological concepts (Knoll, 1997). Olson (1973), in describing the important role projects play in the industrial arts/technology classroom, remarked, "The project represents human creative achievement with materials and ideas and results in an experience of self-fulfillment" (p. 21).

Kurt Y. Michael (michael@csvrgs.k12.va.us) is a Technology Education Teacher at Central Shenandoah Valley Regional Governor's School, Fishersville, Virginia. 
Lewis (1999) reiterated this belief by stating, "Technology is in essence a manifestation of human creativity. Thus, an important way in which students can come to understand it would be by engaging in acts of technological creation" (p. 46). The result of technological creation is the creative product.

The creative product embodies the very essence of technology. The American Association for the Advancement of Science (Johnson, 1989) stated, "Technology is best described as a process, but is most commonly known by its products and their effects on society" (p. 1). A product can be described as a physical object, article, patent, theoretical system, an equation, or new technique (Brogden \& Sprecher, 1964). A creative product is one that possesses some degree of unusualness (originality) and usefulness (Moss, 1966). When given the opportunity for self-expression, a student's project becomes nothing less than a creative product.

The creative product can be viewed as a physical representation of a person's "true" creative ability encapsulating both the creative person and process (Besemer \& O'Quin; 1993). By examining the literature related to the creative person and process, technology educators may gain a deeper understanding of the creative product itself.

\section{The Creative Person}

Inventors such as Edison and Ford have been recognized as being highly creative. Why some people reach a level of creative genius while others do not is still unknown. However, Maslow (1962), after studying several of his subjects, determined that all people are creative, not in the sense of creating great works, but rather, creative in a universal sense that attributes a portion of creative talent to every person. In trying to understand and predict a person's creative ability, two factors have often been considered: intelligence and personality.

\section{Intelligence}

A frequently asked question among educators is "What is the relationship between creativity and intelligence?" Research has shown that there is no direct correlation between creativity and intelligence quotient (I.Q.) (Edmunds, 1990; Hayes, 1990; Moss, 1966; Torrance, 1963). Edmunds (1990) conducted a study to determine whether there was a relationship between creativity and I.Q. Two hundred and eighty-one randomly selected students, grades eight to eleven, from three different schools in New Brunswick, Canada participated. The instruments used to collect data were the Torrance Test of Creative Thinking and the OtisLennon School Ability Test, used to test intellectual ability. Based on a Pearson product moment analysis, results showed that I.Q. scores did not significantly correlate with creativity scores. The findings were consistent with the literature dealing with creativity and intelligence.

On a practical level, findings similar to the one above may explain why I.Q. measures have proven to be unsuccessful in predicting creative performance. Hayes (1990) pointed out that creative performance may be better predicted by isolating and investigating personality traits. 


\section{Personality Traits}

Researchers have shown that there are certain personality traits associated with creative people (e.g., DeVore, Horton, and Lawson, 1989; Hayes, 1990; Runco, Nemiro, \& Walberg, 1998; Stein, 1974). Runco, Nemiro, and Walberg (1998) identified and conducted a survey investigating personality traits associated with the creative person. The survey was mailed to 400 individuals who had submitted papers and/or published articles related to creativity. The researchers asked participants to rate, in order of importance, various traits that they believed affected creative achievement. The survey contained 16 creative achievement clusters consisting of 141 items. One hundred and forty-three surveys were returned reflecting a response of $35.8 \%$. Results demonstrated that intrinsic motivation, problem finding, and questioning skills were considered the most important traits in predicting and identifying creative achievement. Though personality traits play an important part in understanding creative ability, an equally important area of creativity theory lies in the identification of the creative process itself.

\section{The Creative Process}

Creativity is a process (Hayes, 1990; Stein, 1974; Taylor, 1959; Torrance, 1963) that has been represented using various models. Wallas (1926) offered one of the earliest explanations of the creative process. His model consisted of four stages that are briefly described below:

1. Preparation: This is the first stage in which an individual identifies then investigates a problem from many different angles.

2. Incubation: At this stage the individual stops all conscious work related to the problem.

3. Illumination: This stage is characterized by a sudden or immediate solution to the problem.

4. Verification: This is the last stage at which time the solution is tested.

Wallas' model has served as a foundation upon which other models have been built. Some researchers have added the communication stage to the creative process (e.g. Stein, 1974; Taylor, 1959; Torrance, 1966). The communication stage is the final stage of the creative process. At this stage, the new idea confined to one's mind is transformed into a verbal or non-verbal product. The product is then shared within a social context in order that others may react to and possibly accept or reject it. A more comprehensive description of the creative process is captured within a definition offered by Torrance (1966).

Creativity is a process of becoming sensitive to problems, deficiencies, gaps in knowledge, missing elements, disharmonies, and so on; identifying the difficult; searching for solutions, making guesses or formulating hypotheses about the deficiencies, testing and re-testing these hypotheses and possibly modifying and retesting them, and finally communicating the results. (p. 8)

Torrance's definition resembles what some have referred to as problem solving. For example, technology educators Savage and Sterry (1990), 
generalizing from the work of several scholars, identified six steps to the problem-solving process:

- Defining the problem: Analyzing, gathering information, and establishing limitations that will isolate and identify the need or opportunity.

- Developing alternative solutions: Using principles, ideation, and brainstorming to develop alternate ways to meet the opportunity or solve the problem.

- Selecting a solution: Selecting the most plausible solution by identifying, modifying, and/or combining ideas from the group of possible solutions.

- Implementing and evaluating the solution: Modeling, operating, and assessing the effectiveness of the selected solution.

- Redesigning the solution: Incorporating improvements into the design of the solution that address needs identified during the evaluation phase.

- Interpreting the solution: Synthesizing and communicating the characteristics and operating parameters of the solution. (p. 15)

By closely comparing Torrance's (1966) definition of creativity with that of Savage and Sterry's (1990) problem solving process, one can easily see similarities between the descriptions. Guilford (1976), a leading expert in the study of creativity, made a similar comparison between steps of the creative process offered by Wallas with those of the problem solving process proposed by the noted educational philosopher, John Dewey. In doing so, Guilford simply concluded that, "Problem-solving is creative; there is no other kind" (p. 98).

Hinton (1968) combined the creative process and problem solving process into what is now known as creative problem solving. He believed that creativity would be better understood if placed within a problem solving structure. Creative problem solving is a subset of problem- solving based on the assumption that not all problems require a creative solution. He surmised that when a problem is solved with a learned response, then no creativity has been expressed. However, when a simple problem is solved with an insightful response, then a small measure of creativity has been expressed, when a complex problem is solved with a novel solution, then genuine creativity has occurred.

Genuine creativity is the result of the creative process that manifests itself into a creative product. Understanding the creative process as well as the creative person may play an important role in realizing the true nature of the creative product. Though researchers have not reached a consensus as to what attributes make up the creative product (Besemer \& Treffingger, 1981; Joram, Woodruff, Bryson, \& Lindsay, 1992; Stein, 1974), identifying and evaluating the creative product has been a concern of some researchers. Notable, is the work of Moss (1966) and Duenk (1966).

\section{Evaluating the Creative Product in Industrial Arts/Technology Education}

Moss (1966) and Duenk (1966) have arguably conducted the most extensive research establishing criteria for evaluating creative products within industrial arts/technology education. Moss (1966), in examining the criterion problem, concluded that unusualness (originality) and usefulness were the defining 
characteristics of the creative product produced by industrial arts students. A description of his model is presented below:

1. Unusualness: To be creative a product must possess some degree of unusualness [or originality]. The quality of unusualness may, theoretically, be measured in terms of probability of occurrence; the less the probability of its occurrence, the more unusual the product (Moss, 1966, p. 7).

2. Usefulness: While some degree of unusualness is a necessary requirement for creative products, it is not a sufficient condition. To be creative, an industrial arts student's product must also satisfy the minimal principle requirements of the problem situation; to some degree it must "work" or be potentially "workable." Completely ineffective, irrelevant solutions to teacher-imposed or student-initiated problems are not creative (Moss, 1966, p. 7).

3. Combining Unusualness and Usefulness: When a product possesses some degree of both unusualness and usefulness, it is creative. But, because these two criterion qualities are considered variables, the degree of creativity among products will also vary. The extent of each product's departure from the typical and its value as a problem solution will, in combination, determine the degree of creativity of each product. Giving the two qualities equal weight, as the unusualness and/or usefulness of a product increases so does its rated creativity; similarly, as the product approaches the conventional and/or uselessness its rated creativity decreases (Moss, 1966, p. 8).

In establishing the construct validity of his theoretical model, Moss (1966) submitted his work for review to 57 industrial arts educators, two measurement specialists, and six educational psychologists. Results of the review found the proposed model was compatible with existing theory and practice of both creativity and industrial arts. No one disagreed with the major premise of using unusualness and usefulness as defining characteristics for evaluating the creative products of industrial arts students.

To date, little additional research has been conducted to establish criteria for evaluating the creative products of industrial arts and/or technology education students. If technology is best known by its creative products, then technology educators are obligated to identify characteristics that make a product more or less creative. Furthermore, educators must find ways to objectively measure these attributes and then teach students in a manner that enhances the creativity of their products. A possible approach to enhancing product creativity is by incorporating computer simulation technology into the classroom. However, no research has been done in this area to measure the true effect of computer simulation on product creativity. For that reason, other studies addressing computer use in general and product creativity will be explored.

Studies Related to Computers and the Creative Product

A study conducted by Joram, Woodruff, Bryson, \& Lindsay (1992) found that average students produced their most creative work using word processors 
as compared to students using pencil and paper. The researchers hypothesized that word-processing would hinder product creativity due to constant evaluation and editing of their work. To test the hypotheses, average and above average eighth grade writers were randomly assigned to one of two groups. The first group was asked to compose using word processors while the second group was asked to compose using pencil and paper. After collecting the compositions, both the word-processed and handwritten texts were typed so that they would be in the same format for the evaluators. Based on the results, the researchers concluded that word-processing enhances the creative abilities of average writers. The researchers attributed this to the prospect that word-processing may allow the average writer to generate a number of ideas, knowing that only a few of them will be usable and the rest can be easily erased. However, the researchers also found that word-processing had a negative effect on the creativity of above average writers. These mixed results suggest that the use of word-processing may not be appropriate for all students relative to creativity.

Similar to word processing, computer graphic programs may also help students improve the creativeness of their products. In a study conducted by Howe (1992), two advanced undergraduate classes in graphic design were assigned to one of two treatments. The first treatment group was instructed to use a computer graphic program to complete a design project whereas the other group was asked to use conventional graphic design equipment to design their product. Upon completion of the assignment, both groups' projects were collected and photocopied so that they would be in the same format before being evaluated. Based on the results, the researcher concluded that students using computer graphics technology surpassed the conventional method in product creativity. The researchers attributed this to the prospect that computer graphics programs may enable graphic designers to generate an abundance of ideas, then capture the most creative ones and incorporate them into their designs. However, due to a lack of random assignment, results of the study should be generalized with caution.

Like word processing and computer graphics, simulation technology is a type of computer application that allows users to freely manipulate and edit virtual objects. Thus it was surmised that computer simulation may enhance creativity. This notion led to the development of the study reported herein.

\section{Purpose of the Study}

This study compared the effect of a computer simulation activity versus a traditional hands-on activity on students' product creativity. A creative product was defined as one that possesses some measure of both unusualness (originality) and usefulness. The following hypothesis and sub-hypotheses were examined.

\section{Major Research Hypothesis}

There is no difference in product creativity between the computer simulation and traditional hands-on groups. 
Research Sub-Hypotheses

1. There is no difference in product originality between the computer simulation and traditional hands-on groups.

2. There is no difference in product usefulness between the computer simulation and traditional hands-on groups.

\section{Method}

\section{Subjects}

The subjects selected for this study were seventh-grade technology education students from three different middle schools located in Northern Virginia, a middle-to-upper income suburb outside of Washington, D.C. The school system's middle school technology education programs provide learning situations that allow the students to explore technology through problem solving activities. The three participating schools were chosen because of the teachers' willingness to participate in the study.

\section{Materials}

Kits of Classic Lego Bricks ${ }^{\mathrm{TM}}$ were used with the hands-on group. The demonstration version of Gryphon Bricks ${ }^{\mathrm{TM}}$ (Gryphon Software Corporation, 1996) was used with the simulation group. This software allows students to assemble and disassemble computer generated Lego-type bricks in a virtual environment on the screen of the computer. Subjects in the computer simulation group were each assigned to a Macintosh computer on which the Gryphon Bricks software was installed. Each subject in the hands-on treatment group was given a container of Lego bricks identical to those available virtually in the Gryphon software.

\section{Test Instrument}

Products were evaluated based on a theoretical model proposed by Moss (1966). Moss used the combination of unusualness (or originality) and usefulness as criteria for determining product creativity. However, Moss' actual instrument was not used in this study due to low inter-rater reliability. Instead, a portion of the Creative Product Semantic Scale or CPSS (Besemer \& O'Quin, 1989) was used to determine product creativity. Sub-scales "Original" and "Useful" from the CPSS were chosen to be consistent with Moss' theoretical model.

The CPSS has proven to be a reliable instrument in evaluating a variety of creative products based on objective, analytical measures of creativity (Besemer \& O'Quin, 1986, 1987, 1989, 1993). This was accomplished by the use of a bipolar, semantic differential scale. In general, semantic differential scales are good for measuring mental concepts or images (Alreck, 1995). Because creativity is a mental concept, the semantic differential naturally lends itself to measuring the creative product. Furthermore, the CPSS is flexible enough to allow researchers to pick various sub-scales based on the theoretical construct being investigated, like the use of the Original and Useful subscales in this study. In support of this, Besemer and O'Quin (1986) stated, “... the sub-scale 
structure of the total scale lends itself to administration of relevant portions of the instrument rather than the whole" (p. 125).

The CPSS was used in a study conducted by Howe (1992). His reliability analysis, based on Cronbach's alpha coefficient, yielded good to high reliability across all sub-scales of the CPSS. Important to this study were the high reliability results for sub-scales Original (.93) and Useful (.92). These high reliability coefficients are consistent with earlier studies conducted by Besemer and O'Quin (1986, 1987, 1989).

\section{The Pilot Study}

A pilot study was conducted in which a seventh-grade technology education class from a Southwest Virginia middle school was selected. The pilot study consisted of 16 subjects who were randomly assigned to either a hands-on treatment group or a simulation treatment group. As a result of the pilot study, the time allocated for the students to assemble their creative products from 30 minutes to 25 minutes since most of them had finished within the shorter time. Precedence for limiting the time needed to complete a creative task was found in Torrance's (1966) work in which 30 minutes was the time limit for a variety of approaches to measuring creativity.

\section{Procedure}

One class from each of the three participating schools was selected for the study. Fifty-eight subjects participated, 21 females and 37 males, with an average age of 12.4 years. Subjects were given identification numbers, then randomly assigned to either the hands-on or the computer simulation treatment group. The random assignment helped ensure the equivalence of groups and controlled for extraneous variables such as students' prior experience with openended problem solving activities, use of Lego blocks and/or computer simulation programs, and other extraneous variables that may have confounded the results. The independent variable in this study was the instructional activity and the dependent variable was the subjects' creative product scores as determined by the combination of the original and useful sub-scales from the CPSS (Besemer \& O'Quin, 1989).

Subjects in both the hands on and the simulation groups were asked to construct a "creature" that they believed would be found on a Lego planet. The "creature" scenario was chosen because it was an open-ended problem and possessed the greatest potential for imaginative student expression. The only difference in treatment between the two groups was that the hands-on group used real Lego bricks in constructing their products whereas the simulation treatment group used a computer simulator. Treatments were administered simultaneously and overall treatment time was the same for both groups. The hands-on treatment group met in its regular classroom whereas the simulation treatment group met in a computer lab. The classroom teacher at each school proctored the hands-on treatment group and the researcher proctored the simulation treatment group. 
The subjects in the hands-on treatment group were given five-minutes to sort their bricks by color while subjects in the simulation treatment group watched a five-minute instructional video explaining how to use the simulation software. By having the students sort their bricks for five minutes, the overall treatment time was the same for both groups, thus eliminating a variable that may otherwise influence the results. Then, the subjects in both groups were given the following scenario:

Pretend you are a toy designer working for the Lego Company. Your job is to create a "creature" using Lego bricks that will be used in a toy set called Lego Planet. What types of creatures might be found on a Lego planet? Use your creativity and make a creature that is original in appearance yet useful to the toy manufacturer.

One more thing, the creature you construct must be able to fit within a fiveinch cubed box, that means you must stay within the limits of your green base plate and make your creature no higher than 13 bricks.

You will have 25 minutes to complete this activity. If you finish early, spend more time thinking about how you can make your creature more creative. You must remain in your seat the whole time. If there are no questions, you may begin.

When the time was up, the subjects were asked to stop working. The handson treatment group's products were labeled, collected, and then reproduced in the computer simulation software by the researcher. This was done so that the raters could not distinguish from which treatment group the products were created. Finally, the images of the products from both groups were printed using a color printer.

\section{Product Evaluation}

To evaluate the students' solutions, two raters were recruited: a middle school art teacher and a middle school science teacher. The teachers were chosen because of their willingness to participate in the study and had a combined total of 36 years of teaching experience. To help establish inter-rater reliability, a rater training session was conducted during the pilot study. The same teacher-raters used in the pilot study were used in the final study. The training session provided the teacher-raters with instructions on how to use the rating instrument and allowed them to practice rating sample products. During the session, disagreements on product ratings were discussed and rules were developed by the raters to increase consistency. The pilot study confirmed that there was good inter-rater reliability across all the scales and and thus the experimental procedures proceeded as designed. No significant difference in creativity, originality, or usefulness was found between the two treatment groups during the pilot study.

For the actual study, the teacher-raters were each given the printed images of the products from each of the 58 subjects and were instructed to independently rate them using the Original and Useful sub-scales of the CPSS (Besemer \& O'Quin, 1989). Three weeks were allowed for the rating process. 


\section{Findings}

Once the ratings from the two raters had been obtained, an inter-rater reliability analysis, based on Cronbach's alpha coefficient, was conducted. Analysis yielded moderate to good inter-rater reliability (.74 to .88 ) across all the scales. The stated hypotheses were then tested using one-way analysis of variance (ANOVA).

- No difference in product Creativity scores was found between the computer simulation group $(M=41.7, S D=7.67)$ and the hands-on group $(M=42.0, S D=5.58)$. Therefore the null hypothesis was not rejected, $F(5,52)=0.54, p=0.75$.

- No difference in product Originality scores was found between the computer simulation group $(M=20.59, S D=4.44)$ and the hands-on group $(M=21.10, S D=3.10)$. Thus, the null hypothesis was not rejected, $F(5,52)=1.07, p=0.39$.

- No difference in product Usefulness scores between the computer simulation group $(M=21.15, S D=4.17)$ and the traditional hands-on group $(M=20.90, S D=3.20)$. Once again, the researcher failed to reject the null hypothesis, $F(5,52)=0.49, p=0.78]$.

\section{Conclusion}

Though there are only a few empirical studies to support their claims, some researchers believe that computers in general may improve student product creativity by allowing students to generate an abundance of ideas, capture the most creative ones, and incorporate them into their product (Howe, 1992; Joram, Woodruff, Bryson, \& Lindsay, 1992). Similarly, some researchers speculate that the use of computer simulations may enhance product creativity as well (Betz, 1996; Gokhale, 1996; Harkow, 1996). However, based on the results of this study, the use of computer simulation to enhance product creativity was not supported. The creativity, usefulness, or originality of the resulting products appears to be the same whether students use a computer simulation of Lego blocks or whether they manipulated the actual blocks.

Because the simulation activity in this study was nearly identical to the hands-on task, one might conclude that product creativity may be more reliant upon the individual's creative cognitive ability rather than the tools or means by which the product was created. This would stand to reason based on Besemer and O'Quin's (1993) belief that the creative product is unique in that it combines both the creative person and process into a tangible object representing the "true" measure of a person's creative ability. With this in mind, when studying a computer simulation's effect on student product creativity, researchers may want to focus more attention on the creative person's traits and the cognitive process used to create the product rather than focusing on the tool or means by which the product was created. This approach to understanding student product creativity may lend itself more to qualitative rather than quantitative research.

If quantitative research is to continue in this area of study, researchers may wish to consider using a different theoretical model and instrument for 
measuring the creative product. For example, if replicating this experiment, rather than using only the two sub-scales of the Creative Product Semantic Scale (Bessemer \& O'Quin, 1989), the complete instrument might be used, yielding additional dimensions of creativity. Additional research regarding the various types of simulation programs is needed, along with the different effects they might have on student creativity in designing products. The use of computer simulations in technology education programs appears to be increasing with little research to support their effectiveness or viable use.

\section{References}

Alreck, T.L., \& Settle, B.R. (1995). The survey research handbook $\left(2^{\text {nd }}\right.$ Ed. $)$. Chicago: Irwin Inc.

Besemer, S.P., \& O'Quin, K. (1993). Assessing creative products: Progress and potentials. In S.G. Isaksen (Ed.), Nurturing and developing creativity: The emergence of a discipline (pp. 331-349). Norwood, New Jersey: Ablex Publishing Corp.

Besemer, S.P., \& O'Quin, K. (1989). The development, reliability and validity of the revised creative product semantic scale. Creativity Research Journal, 2, 268-279.

Besemer, S.P., \& O'Quin, K. (1987). Creative product analysis: Testing a model by developing a judging instrument. In S.G. Isaksen, Frontiers of creativity research: Beyond the basics. (pp. 341-357). Buffalo, NY: Bearly Ltd.

Besemer, S.P., \& O'Quin, K. (1986). Analysis of creative products: Refinement and test of a judging instrument. Journal of Creative Behavior, 20 (2), 115126.

Besemer, S.P., \& Treffingger, D. (1981). Analysis of creative products: Review and synthesis. Journal of Creative Behavior, 15, 158-178.

Betz, J.A. (1996). Computer games: Increase learning in an interactive multidisciplinary environment. Journal of Technology Systems, 24 (2), 195 205.

Bilan, B. (1992). Computer simulations: An Integrated tool. Paper presented at the SAGE/ $6^{\text {th }}$ Canadian Symposium, The University of Calgary.

Brogden, H., \& Sprecher, T. (1964). Criteria of creativity, In Taylor, C.W., Creativity, progress and potential. New York: McGraw Hill.

Choi, B., \& Gennaro, E. (1987). The effectiveness of using computer simulated experiments on junior high students' understanding of the volume displacement concept. Journal of Research in Science Teaching, 24 (6), 539-552.

DeVore, P., Horton, A., \& Lawson, A. (1989). Creativity, design and technology. Worcester, Massachusetts: Davis Publications, Inc.

Duenk, L.G. (1966). A study of the concurrent validity of the Minnesota Test of Creative Thinking, Abbr. Form VII, for eighth grade industrial arts student. Minneapolis: Minnesota University. (Report No. BR-5-0113).

Edmunds, A.L. (1990), Relationships among adolescent creativity, cognitive development, intelligence, and age. Canadian Journal of Special Education, $6(1), 61-71$. 
Gokhale, A.A. (1996). Effectiveness of computer simulation for enhancing higher order thinking. Journal of Industrial Teacher Education, 33 (4), 3646.

Gryphon Software Corporation (1996). Gryphon Bricks Demo (Version 1.0) [Computer Software]. Glendale, CA: Knowledge Adventure. [On-line] Available: http://www.kidsdomain.com/down/mac/bricksdemo.html

Guilford, J. (1976). Intellectual factors in productive thinking. In R. Mooney \& T. Rayik (Eds.), Explorations in creativity. New York: Harper \& Row.

Harkow, R.M. (1996). Increasing creative thinking skills in second and third grade gifted students using imagery, computers, and creative problem solving. Unpublished master's thesis, NOVA Southeastern University.

Hayes, J.R. (1990). Cognitive processes in creativity. (Paper No. 18).University of California Berkeley.

Hinton, B.L. (1968, Spring). A model for the study of creative problem solving. Journal of Creative Behavior, 2(2), 133-142.

Howe, R. (1992). Uncovering the creative dimensions of computer-graphic design products. Creativity Research Journal, 5 (3), 233-243.

Johnson, J.R. (1989). Project 2061: Technology (Association for the Advancement of Science Publication 89-06S). Washington, DC.: American Association for the Advancement of Science.

Joram, E., Woodruff, E., Bryson, M., \& Lindsay, P. (1992). The effects of revising with a word processor on writing composition. Research in the Teaching of English, 26 (2), 167-192.

Knoll, M. (1997). The project method: Its vocational education origin and international development. Journal of Industrial Teacher Education, 34(3), 59-80.

Lewis, T. (1999). Research in technology education: Some areas of need. Journal of Technology Education, 10 (2), 41-56.

Maslow, A. (1962). Toward a psychology of being. Princeton, NJ: Van Nostrand.

Moss, J. (1966). Measuring creative abilities in junior high school industrial arts. Washington, DC: American Council on Industrial Arts Teacher Education.

Olson, D.W. (1973). Tecnol-o-gee. Raleigh: North Carolina University School of Education, Office of Publications.

Runco, R.A., Nemiro, J., \& Walberg, H.J., (1998). Personal explicit theories of creativity. Journal of Creative Behavior, 32(1), 1-17.

Savage, E., \& Sterry, L. (1990). A conceptual framework for technology education. Reston, VA: International Technology Education Association.

Stein, M. (1974). Stimulating creativity: Vol. 1. Individual procedures. New York: Academic Press.

Taylor, I.A. (1959). The nature of the creative process. In P. Smith (Ed.), Creativity: An examination of the creative process (pp. 51-82). New York: Hastings House Publishers.

Torrance, E. P. (1966). Torrance test on creative thinking: Norms-technical manual (Research Edition). Lexington, Mass: Personal Press. 
Torrance, E.P. (1963). Creativity. In F. W. Hubbard (Ed.), What research says to the teacher (Number 28). Washington, DC: Department of Classroom Teachers American Educational Research Association of the National Education Association.

Wallas, G. (1926). The art of thought. New York: Harcourt, Bruce and Company. 